\title{
Noves dades sobre el mecanisme neural de la consolidació de la memòria: una oportunitat per a atenuar l'impacte emocional de les experiències traumàtiques
}

\author{
ENRIQUE LANUZA (Enrique.Lanuza@uv.es) \\ Universitat de València
}

\section{Introducció}

És probable que el lector recorde on es trobava quan li va arribar la notícia dels atacs sobre les torres bessones de Nova York l'11 de setembre de 2001. El fet és que les memòries amb una forta càrrega emocional són especialment indelebles, i el seu record, tot i el pas del temps, sol estar indissolublement lligat a la càrrega emocional original. Quan aquest tipus de memòria es genera arran d'una experiència traumàtica, en alguns casos dóna lloc a un trastorn per estrès posttraumàtic. Les persones que pateixen aquest trastorn reviuen de manera intensa la situació traumàtica original, cosa que afecta de manera molt important la seua qualitat de vida.

El trastorn per estrès posttraumàtic va començar a estudiar-se de manera sistemàtica en els veterans de la guerra del Vietnam, i ara es reconeix que la gran majoria de les persones que sobreviuen a una experiència traumàtica desenvolupen estrès posttraumàtic (Yehuda i McFarlane, 1997). Aquestes persones pateixen ansietat crònica, insomni, atacs de pànic, dificultat de concentració, un estat d'alerta permanent, reaccions desmesurades de por davant forts sorolls o altres estímuls, somnis recurrents de l'experiència traumàtica i altres símptomes semblants. Naturalment, aquest conjunt de fenòmens dificulta molt notablement el desenvolupament d'una vida normal. Actualment es reconeix la síndrome d'estrès posttraumàtic en dones violades, infants i dones maltractades (que han patit violència física i/o abús sexual), persones que han patit un accident de trànsit greu o qualsevol tipus d'experiència traumàtica (Pitman i altres, 2000).

El tractament d'aquest tipus de memòries traumàtiques és difícil, atesa la seua resistència a l'extinció, és a dir, a anar perdent la càrrega emocional a mesura que es recorden en un ambient segur.

\section{La base neural de les memòries emocionals}

Experiments amb animals ens han revelat que una estructura cerebral clau per a la generació de memòries emocionals és l'amígdala, un grup neuronal situat a la part ventral i medial del lòbul temporal (LeDoux, 2000). L'amígdala rep informació sobre l'experiència traumàtica per diferents canals sensorials i l'associa amb els altres estímuls (visuals, auditius, olfactius) que tenen lloc a la vegada, i amb el context on aquesta experiència ocorre 


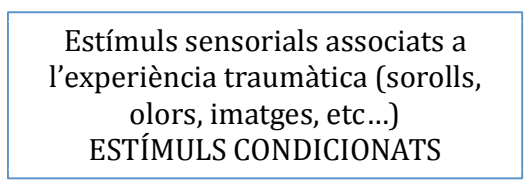

Estímuls derivats de l'experiència traumàtica ESTÍMULS INCONDICIONATS

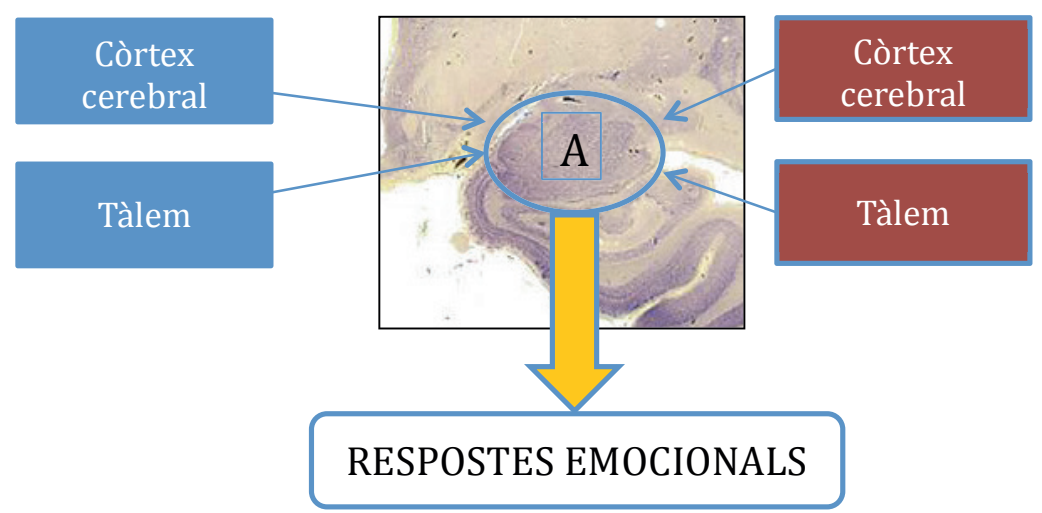

Figura 1. Secció coronal del lòbul temporal d'un cervell humà, en el que es pot observar l'amígdala (A), $i$ representació esquemàtica de les principals vies neurals implicades en l'aprenentatge emocional.

(Figura 1). L'associació entre l'experiència traumàtica i el context o els altres estímuls simultanis farà que, posteriorment, els sons, les imatges, les olors o el context recorden aquella experiència i desencadenen les mateixes respostes emocionals (por, ansietat, pànic, etc.). Aquest tipus d'aprenentatge es coneix com a condicionament pavlovià, pel treball del fisiòleg rus Ivan Pàvlov. Els estímuls derivats de l'experiència traumàtica s'anomenen estímuls incondicionats, mentre que els estímuls neutres que queden associats amb l'esmentada experiència s'anomenen estímuls condicionats (Figura 1).

En el cas de l'experimentació amb rates de laboratori, aquest condicionament pavlovià s'aconsegueix, freqüentment, amb la presentació reiterada d'un estímul neutre (normalment un xiulit monotonal, un to) seguida d'un lleuger xoc elèctric a les potes (inofensiu, però aversiu per a l'animal). Després d'unes poques presentacions de tons seguits de xocs, els animals mostren comportaments defensius a la presentació dels tons tots sols. L'amígdala, possiblement junt amb altres estructures cerebrals, és clau tant per a l'adquisició d'aquestes associacions entre els tons i els xocs com per al record de les memòries emocionals resultants (Maren i Quirk, 2004).

Les dades sobre el paper de l'amígdala en animals han estat confirmades majoritàriament en persones utilitzant experiments de ressonància magnètica funcional (Sehlmeyer i altres, 2009) així com casos esporàdics de lesions cerebrals que afecten l'amígdala (Bechara i altres, 1995). Els pacients d'una malaltia rara, la síndrome d'Urbach-Wiethe, que causa la calcificació de l'amígdala als dos hemisferis cerebrals, han confirmat aquesta idea. Aquestes persones mostren una absència de respostes de por a tots els estímuls experimentats (Feinstein i altres, 2011) excepte a la inhalació de diòxid de carboni (Feinstein i altres, 2013). De fet, la pacient coneguda per les inicials SM va explicar als investigadors, després de l'experiment amb la inhalació de diòxid de carboni, que havia sentit por per primera vegada 
en la seua vida. Per tant, les dades sobre el paper de l'amígdala en les memòries emocionals derivades dels experiments amb animals semblen extrapolables als humans. Aquest resultat és raonable atès que l'estructura de l'amígdala es troba molt conservada evolutivament, i és bastant semblant al cervell de rèptils, aus i mamífers (Martínez-García i altres, 2007).

La càrrega emocional de les memòries es troba modulada per l'acció de l'adrenalina i la noradrenalina sobre l'amígdala (Cahill i McGaugh, 1998). Aquest efecte s'ha demostrat tant en relació amb l'adrenalina perifèrica (en sang), com en l'àmbit intracerebral, atès que hi ha una projecció que utilitza noradrenalina com a neurotransmissor i que innerva l'amígdala (Tully i Bolshakov, 2010). Les neurones de l'amígdala tenen receptors per a adrenalina i noradrenalina de tipus adrenoreceptor $\beta$. Per tant, com veurem després, l'efecte de l'adrenalina i la noradrenalina sobre aquest tipus de receptors és una possible diana terapèutica sobre la qual s'ha d'actuar per a atenuar la càrrega emocional de les memòries traumàtiques.

\section{La reconsolidació de la memòria}

La generació de noves memòries té diverses fases. La primera és l'adquisició, que ocorre durant l'experiència que dóna lloc a la nova memòria i que genera una memòria a curt termini. A continuació, la nova memòria ha de ser consolidada. Aquesta fase de consolidació requereix, per a aconseguir una memòria a llarg termini, l'expressió de determinats gens i la síntesi de noves proteïnes (Figura 2).

\section{Adquisició $\rightarrow$ Memòria a curt termini $\rightarrow$ Consolidació $\rightarrow$ Memòria a llarg termini $\rightarrow$ Reactivació $\rightarrow$ Reconsolidació}

Figura 2. Fases temporals que s'observen en la generació d'una memòria. En un altre color, els processos de rememoració i la posterior reconsolidació.

Una vegada la memòria es troba emmagatzemada, pot ser recuperada (és a dir, recordada o rememorada) en un context similar o pels estímuls associats a l'experiència original. Aquesta fase s'anomena expressió o reactivació de la memòria. Fins als darrers anys del segle $\mathrm{xx}$, els científics pensaven que una memòria, una vegada reactivada, era emmagatzemada de nou sense ser alterada. Tanmateix, dos treballs independents en animals experimentals van mostrar que, immediatament després de la reactivació o rememoració, les memòries requereixen un nou procés de consolidació, anomenat reconsolidació (Przybyslawski i Sara, 1997; Nader i altres, 2000). La reconsolidació requereix de nou expressió gènica i nova síntesi de proteïnes. Per tant, interferir en aquests processos durant la finestra temporal en què té lloc la reconsolidació bloqueja el procés i impedeix el nou emmagatzematge. Més important, l'existència de la reconsolidació revela que la memòria, una vegada reactivada, es torna làbil, i per tant modificable. Això vol dir que immediatament després del procés de reactivació aquells factors que puguen influir sobre la memòria (fent-la, per exemple, menys traumàtica), faran que la memòria siga reconsolidada al nou estat. És evident que aquesta finestra temporal en la qual una memòria és modificable obri una possibilitat terapèutica molt important per al tractament de les memòries traumàtiques. 


\section{Aproximació farmacològica per a atenuar la càrrega emocional d'una memòria traumàtica durant el període de reconsolidació}

Com hem comentat al final del punt 2 , les situacions amb una forta càrrega emocional activen les neurones noradrenèrgiques d'una estructura del tronc de l'encèfal denominada locus ceruli ("lloc blau" en llatí) que innerva l'amígdala. De fet, des dels anys 1990 se sap que el blocatge de la neurotransmissió noradrenèrgica amb un antagonista d'adrenalina després d'un esdeveniment emocionalment intens evita l'augment de la intensitat de la memòria característic de les memòries emocionals (Cahill i altres, 1994). Per tant, aquest tractament és útil per a reduir el risc de desenvolupar el trastorn per estrès posttraumàtic, però requereix l'administració del fàrmac en una finestra temporal relativament curta després de l'experiència traumàtica, quan és poc probable que la persona estiga ja en tractament clínic i tinga accés al fàrmac.

El fet que les memòries es tornen de nou làbils quan són rememorades i requereixen un nou procés de consolidació obri la possibilitat de tractar-les amb aquest tipus de fàrmacs antagonistes d'adrenalina al llarg de tota la vida. Aquesta aproximació farmacològica s'ha demostrat efectiva en animals d'experimentació (Przybyslawski i altres, 1999), utilitzant l'antagonista propranolol, tant mitjançant l'administració intracerebral d'aquest a l'amígdala com amb la injecció sistèmica del fàrmac (Debiec i LeDoux, 2004), atès que aquest travessa la barrera hematoencefàlica i per tant pot actuar en el cervell. El propranolol és un fàrmac blocador $\beta$ (antagonista de receptors d'adrenalina de tipus $\beta$ ) que s'utilitza per al tractament de malalties cardiovasculars, relativament segur i amb pocs efectes secundaris. Això ha permès estudiar el seu efecte en la reconsolidació de memòries emocionals, tant en voluntaris (Schwabe i altres, 2012; 2013) com en pacients de trastorn per estrès posttraumàtic (Brunet i altres, 2008; Menzies, 2012). Els experiments amb voluntaris han mostrat que el propranolol administrat just abans de la reactivació de la memòria disminueix tant l'increment de la intensitat de la memòria del fet emocional com la càrrega emocional de la vivència subjectiva que acompanya el record d'aquesta memòria (Schwabe i altres, 2012; 2013). Les proves amb pacients, tot i que encara preliminars, mostren que el tractament va ser beneficiós reduint el nombre de vegades que les memòries traumàtiques eren rememorades, així com l'angoixa associada a aquestes experiències (Menzies, 2012).

En aquesta aproximació farmacològica és molt important ressaltar la importància de la pauta temporal en què ha de ser administrat el fàrmac blocador ß. És crític que el fàrmac siga efectiu durant la fase de reconsolidació de la memòria que ocorre després de la rememoració. Per tant, cal administrar-lo immediatament abans d'una sessió terapèutica conduïda per un professional en la qual els pacients han de recordar l'experiència traumàtica.

\section{Aproximació comportamental per a atenuar la càrrega emocional d'una memòria traumàtica durant el període de reconsolidació}

L'aproximació farmacològica descrita és prometedora, però recentment s'ha descrit una possibilitat d'interferir en la reconsolidació d'una memòria emocional mitjançant una metodologia comportamental que no requereix cap fàrmac (Monfils i altres, 2009). 
Aquesta aproximació es basa en la reactivació de la memòria i la subseqüent realització d'un procés d'extinció dins de la finestra temporal en la qual té lloc la reconsolidació de la memòria reactivada. L'extinció és el procés mitjançant el qual la càrrega emocional d'un estímul que ha estat associat amb una experiència traumàtica s'atenua a mesura que la seua presentació ja no ocorre al costat de cap experiència desagradable. En el cas de l'experimentació animal, l'extinció s'aconsegueix amb presentacions repetides del to (que prèviament s'ha associat al xoc) però ara sense ser seguit de cap estímul aversiu (l'estímul incondicionat). Al cap de diverses presentacions del to, l'animal va deixant de respondre amb comportaments defensius. L'extinció, tanmateix, no és un procés d'oblit de l'associació entre el to i el xoc, sinó un nou aprenentatge en el qual l'animal reaprén que el to ja no és un senyal que prediu l'estímul incondicionat. Tanmateix, l'associació original entre el to i el xoc no desapareix, simplement és inhibida i ja no s'expressa. Però la memòria aversiva original pot reaparèixer en determinades circumstàncies, per exemple quan el to és presentat en un context nou, diferent del context en què va realitzar-se l'extinció. Per això es diu que l'extinció és un aprenentatge depenent del context (Bouton i Ricker, 1994).

El descobriment del procés de reconsolidació de les memòries ens ha mostrat que aquestes es tornen làbils i, per tant, modificables durant un temps determinat després de la reactivació de la memòria. Què pot ocórrer si es produeix el procés d'extinció dins d'aquesta finestra temporal? Aquesta pregunta ha estat contestada experimentalment tant en rates de laboratori (Monfils i altres, 1999) com amb persones voluntàries (Schiller i altres, 2010). Els resultats dels experiments en rates de laboratori mostren que la reactivació de la memòria seguida de l'extinció interfereix en el procés de reconsolidació, de tal manera que els subjectes ja no expressen respostes defensives a la presentació del to i, a més a més, aquesta manca de respostes no és sensible al context, com ocorre en el cas de l'extinció clàssica. Aquests resultats suggereixen que l'associació prevalent que queda emmagatzemada no és entre el to i el xoc, sinó entre el to i l'absència d'estímuls aversius.

El fet que l'extinció siga depenent de context és un dels problemes que es troben en les teràpies comportamentals dels trastorns d'ansietat basades en l'extinció d'aquestes respostes emocionals. A més de la reaparició de les memòries emocionals en contextos diferents o nous, aquests trastorns també poden reaparèixer després de les sessions d'extinció a causa de l'exposició esporàdica a l'estímul aversiu o simplement de manera espontània amb el pas del temps (Schiller i altres, 2008). Els resultats experimentals amb animals mostren que la interferència de la reconsolidació de la memòria mitjançant el procés d'extinció resulta en una aparent desaparició de l'associació entre el to i el xoc original que no reapareix, ni en contexts nous, ni després d'un temps (un mes en el cas de les rates d'aquest experiment), ni després de la presentació de l'estímul incondicionat (Monfils i altres, 2009). Per tant, aquestes dades indiquen que la nova associació entre el to i la manca d'estímul incondicionat ha reescrit la memòria prèvia. De nou, com ja hem ressaltat en el cas del tractament amb el propranolol, per a obtenir els efectes descrits, la pauta temporal de presentació dels estímuls té un paper crític. En rates de laboratori, l'extinció és efectiva per a reescriure la memòria prèvia si té lloc entre deu minuts i una hora després de la reactivació de la memòria, mentre que no és diferent d'una extinció clàssica si es realitza més de sis hores després de la reactivació (Monfils i altres, 1999). 
Aquesta aproximació comportamental s'ha demostrat útil també en persones voluntàries (Schiller i altres, 2010). En aquest cas, els experiments han consistit en la visualització de quadrats de diferents colors mostrats en la pantalla d'un ordinador, de manera que un color determinat (estímul condicionat) va seguit d'un lleuger xoc elèctric al canell (estímul incondicionat). La resposta mesurada fou la conductància galvànica de la pell (un mesurament de l'increment de transpiració produït per la por o l'ansietat), que augmenta en resposta al xoc i s'observa en resposta a l'estímul condicionat després d'haver-se produït l'associació. Els resultats d'aquests experiments són molt semblants als obtinguts amb rates de laboratori, és a dir, la realització d'un protocol d'extinció deu minuts després de la reactivació de la memòria va evitar la recuperació de la memòria aversiva que sí que va aparèixer en el cas dels protocols d'extinció realitzats sense la reactivació prèvia o sis hores després de la reactivació, quan la memòria ja s'havia reconsolidat (Figura 3).

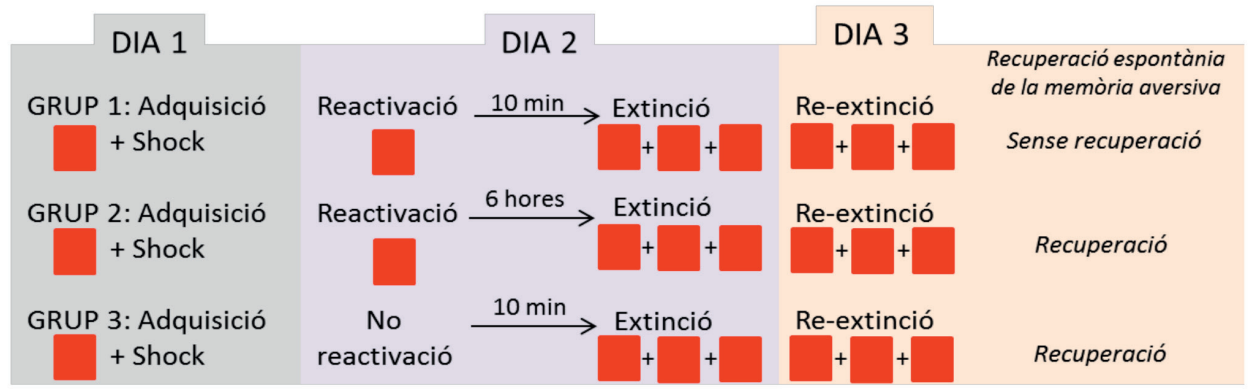

Figura 3. Esquema de protocol comportamental desenvolupat en Schiller i altres (2010) per tal d'interferir en la reconsolidació de la memòria aversiva realitzant un procés d'extinció després de la reactivació de la mateixa. La mesura de la recuperació espontània de la resposta és la diferència entre la resposta galvànica de la pell observada en la primera presentació de l'estímul condicionat el dia 3 respecte a l'observada en la darrera presentació de l'extinció duta a terme el dia 2.

Altres experiments mostraren que aquesta desaparició de la memòria aversiva va ser estable, observant-se fins i tot un any després (Schiller i altres, 2010). Més recentment, la realització d'un protocol experimental semblant al descrit mentre els subjectes voluntaris eren sotmesos a una ressonància magnètica funcional (que permet la visualització de les àrees del cervell actives durant la realització d'una determinada tasca, el que es coneix com una neuroimatge) ha revelat que la reactivació i subseqüent reconsolidació d'una memòria aversiva dóna lloc a una activitat característica a l'amígdala, que en canvi desapareix si durant el procés de reconsolidació es realitza un protocol d'extinció (Agren i altres, 2012).

En conclusió, les dades experimentals indiquen que les memòries emocionals (i possiblement també altres tipus de memòries) es tornen làbils una vegada rememorades, $\mathrm{i}$ requereixen un procés de reconsolidació que dura menys de sis hores, durant el qual són modificables tant amb tractaments farmacològics com amb teràpies comportamentals. El coneixement d'aquest procés bàsic del mecanisme d'emmagatzematge de la nostra memòria obri la possibilitat d'una intervenció terapèutica innovadora en els trastorns d'ansietat que tenen com a origen memòries d'experiències traumàtiques. 


\section{BIBLIOGRAFIA}

Agren, T. i altres (2012): «Disruption of reconsolidation erases a fear memory trace in the human amygdala», Science, setembre, 21, 337(6101), 1550-2.

Bechara, A. i altres (1995): «Double dissociation of conditioning and declarative knowledge relative to the amygdala and hippocampus in humans», Science, 269(5227), 1115-8.

Bouton, M.E. i S.T. Ricker (1994): «Renewal of extinguished responding in a second context», Animal Learning and Behavior, 22, 317-324.

BRUnET, A. i altres (2008): «Effect of post-retrieval propranolol on psychophysiological responding during subsequent script-driven traumatic imagery in post-traumatic stress disorder», Journal of Psychiatric Research, 42, 503-506.

CAHILl, L. i altres (1994): «Beta-adrenergic activation and memory for emotional events», Nature, 371, 702-704.

CAhILl, L. i J.L. McGaugh (1998): «Mechanisms of emotional arousal and lasting declarative memory», Trends Neuroscience, 21, 294-9.

Debiec, J. i J.E. LeDoux (2004): «Disruption of reconsolidation but not consolidation of auditory fear conditioning by noradrenergic blockade in the amygdala», Neuroscience, 129, 267-272.

Feinstein, J.S. i altres (2011): «The human amygdala and the induction and experience of fear», Current Biology, 21, 34-38.

Feinstein, J.S. i altres (2013): «Fear and panic in humans with bilateral amygdala damage», Nature Neuroscience, 16, 270-2.

LeDoux, J.E. (2000): «Emotion circuits in the brain», Annual Review of Neuroscience, 23, 155-84.

Maren, S. i G.J. Quirk(2004): «Neuronal signalling of fear memory», Annual Review of Neuroscience, 5, 844-52.

Martínez-García, F. i altres (2007): «Evolution of the amygdala in vertebrates», dins KaAs, J.H. (ed.): Evolution of Nervous Systems, Oxford, Academic Press, 255-334.

Menzies, R.P. (2012): «Propranolol, traumatic memories, and amnesia: a study of 36 cases», Journal of Clinical Psychiatry, 73, gener, 129-130.

MonfiLs, M.H. i altres (2009): «Extinction-reconsolidation boundaries: key to persistent attenuation of fear memories», Science, 15, maig, 324(5929), 951-5.

NADER K. i altres (2000): «Fear memories require protein synthesis in the amygdala for reconsolidation after retrieval», Nature, 406, 722-726.

Pitman, R.K. i altres (2000): «Posttraumatic stress disorder», dins GazZaniga, M.S. (ed.): The New Cognitive Neurosciences, Cambridge, The MIT Press.

PrZybyslawski, J. i altres (1999): «Attenuation of emotional and nonemotional memories after their reactivation. Role of $\beta$-adrenergic receptors», Journal of Neuroscience, 19, 6623-6628.

Przybyslawski, J. i S.J. SARA(1997): «Reconsolidation of memory after its reactivation», Behavioural Brain Research, 84, 241-246.

SCHILlER, D. i altres (2008) «Evidence for recovery of fear following immediate extinction in rats and humans», Learning and Memory, 28, maig, 15(6), 394-402.

SCHILLER, D. i altres (2010): «Preventing the return of fear in humans using reconsolidation update mechanisms», Nature, 7, gener, 463(7277), 49-53.

SCHILLER, D. i altres (2013): «Extinction during reconsolidation of threat memory diminishes prefrontal cortex involvement», Proceedings of the National Academy of Sciences of the United States of America, 10, desembre, 110(50), 20040-5.

SCHWABE, L. i altres (2012): «Neural signature of reconsolidation impairments by propranolol in humans», Biological Psychiatry, 71(4), 380-6.

Schwabe, L. i altres (2013) « $\beta$-Adrenergic blockade during reactivation reduces the subjective feeling of remembering associated with emotional episodic memories», Biological Psychology, febrer, 92(2), 227-32.

SEHLMEYER, C. i altres (2009): «Human fear conditioning and extinction in neuroimaging: a systematic review», PLOS One, 4(6), e5865. 
Tully, K. i V.Y. Bolshakov (2010): «Emotional enhancement of memory: How norepinephrine enables synaptic plasticity», Molecular Brain, 3, 15.

Yehuda, R. i A.C. McFarlane (1997): «Psychobiology of post-traumatic stress disorder», Annals of the New York Academy of Science, Vol. 821.

\section{BIONOTA}

\section{Enrique Lanuza Navarro}

PhD. Professor Titular del Departament de Biologia Cel·lular de la Universitat de València. Va ser becari predoctoral de la Fundació la Caixa a la State University of New York (1995-1997) i investigador post-doctoral Fulbright a la New York University (1999). Investiga els circuits neurals subjacents als comportaments innats, com ara la por, l'atracció sexual, l'agressió o el comportament parental. 